Keywords: Dementia; DSM-5; Neurocognitive disorders; Mild Cognitive Impairment; Mild Neurocognitive Disorder.

\title{
Dementia DSM-IV/ICD-10 or neurocognitive disorder DSM-5?
}

\section{Joaquim Pujol Domenech* Pilar de Azpiazu Artigas ${ }^{\star \star}$}

${ }^{*}$ Psychiatrist, Neurologist and Professor for the Masters in Geriatric Psychiatry at the Autonomous University of Barcelona

** Psychiatrist and Professor for the Masters in Geriatric Psychiatry at the Autonomous University of Barcelona. M.D. Psychogeriatric Area CASM Benito Menni, Sant Boi de Llobregat. Barcelona

SPAIN

\begin{abstract}
Background and Objectives: According to existing data the term dementia was invented in the first century BC. It was introduced in the European literature in the 17th and 18th centuries AC. At the end of the 17th century, the French Encyclopedia points at ethiological implications which would later shape legal concepts. In the 19th century the Centroeuropean research develops specific nosologies until, in the 20th century, senile dementia is gradually discredited.

Methods: Slightly over ten years ago, the Mild Cognitive Disorder (MCD) conceptualization was introduced as an early stage of Alzheimer's disease (AD), but the lack of coherence in relation to lesions sparked a still ongoing controversy, as the author of the MCD concept belongs to the Writing Board of DSM 5.

Results: The DSM IV focuses on a categorical approach in spite of the difficulty in differentiating "normal" from "pathological" impairment at certain ages. On the other hand, the DSM 5 adopts the Dimensional System with a Mild or Severe Neurocognitive Disorder definition, which is necessarily arbitrary and imposes a statistical criterion. The widespread use of this classification would imply diagnosing a large proportion of the population with huge social and medical implications. This triggered a variety of reactions, such as the APA note which claims that DSM 5 and CIE-10 "virtually contain the same codes". However a WHO study revealed that $70 \%$ of surveyed psychiatrists used CIE 10 criteria.

Conclusions: The DSM 5 gives weight to cognitive aspects using as a severity criterion the number of standard deviations in relation to psychometric normality. It might be misleading if applied to some forms of dementia, for instance frontal dementias. The CIE-10 and DSM IV criteria are more operational.
\end{abstract}




\section{Introduction}

According to historians and linguists, the term 'dementia' appeared in the first century BC. It was used by Lucretius in De rerum natura to mean madness or delirium ${ }^{1}$ and by Cicero in De Senectute to refer to madness and the loss of faculties in elderly dementia ${ }^{2}$, which was probably the first reference to include senility as a decisive factor. In later European terminology, it features in the Oxford English Dictionary (1644) ${ }^{3}$, The Physical Dictionary by Blancard (1726) and the Diccionario Español de Sobrino (1791) ${ }^{4}$. On these publications, the term is described as an expression of madness or loss of reason.

It is widely known that the conceptual content of terms is reviewed from one era to the next. It is interesting therefore to note that this term and its concept were sustained from the first century BC until the end of the 18th century, when it was defined by Diderot and d'Alambert as "a disease consisting of a paralysis of the spirit characterized by abolition of the reasoning faculty [...]". They highlight that it differs from delirium and mania and is caused by the inability of brain fibres to react to stimuli ${ }^{5}$. Shortly afterwards, in his Nosographie Méthodique (1771), Boissier de Sauvages refers to the feeble-mindedness of the elderly, the imbélicité du veillard, which he puts down to "a stiffening of the nerve fibres making the elderly less responsive to external stimuli". It also includes an assessment of the legal capacity and responsibility of patients. Pierre Pinel takes this idea one step further in his Nosographie of 1798, where he recognizes amentia and morosis as cognitive disorders. More specifically, these disorders include a failure to link ideas, an extravagant behavioural comportment, superficial emotions, memory loss, difficulty in perceiving objects, a lack of judgement, carrying out activities without a purpose and forgetting words or gestures to express ideas. All of the above summarise the concept of senility when referring to the elderly ${ }^{7}$.

Four decades later, E. Esquirol and Calmeil in Des maladies mentales (1835) defined the concept of dementia as a mental illness characterised by the impairment of reason and comprehension, impulsive behaviour accompanied by decreased memory performance, a reduced attention span and of the ability to make judgements. They also made a comparison for differences with mental retardation between the impoverished rich (dementia) with the poor (mental retardation $)^{8,9}$.

From this point forward, numerous writers went on to develop the concept in a variety of ways. Guislain highlighted the difference between youths and the elderly. Cullen coined the term 'senile dementia', whilst Bayle demonstrated the cerebral cause through chronic arachnoiditis of the general paresis ${ }^{10}$. From then on, schools in Central Europe took up the reins, tackling the subject from different angles. Griesinger, Alzheimer, Perusini ${ }^{11}$ and Pick $^{12}$ used clinical judgment and followed an anatomopathological approach. Cajal focused on the anatomy of the central nervous system, whilst Kraepelin was known for his ingenious rhetorical approach.

The situation remained stable until the 1950s, when the contributions of Roth, and Slater ${ }^{13,14}$ demonstrated the correspondence of damage between so-called senile dementia and Alzheimer's disease. This allowed the concept of senile dementia to be removed as a disease in its own right, laying the conceptual foundations of ICD-10 and DSM-IV for dementia.

More than 2000 years have gone by since the first century BC.

The objective reality or the real object (in this case dementia patients) lacks meaning 
until this reality has been captured and characterised by a specific doctrine or as part of theoretical thinking, acquiring meaning when the real object becomes formal ${ }^{15}$, dementia into Alzheimer's disease using DSM-IV or into Neurocognitive Disorder using DSM-5.

An entity can be characterised using one of three approaches:

- The categorical approach, based on the presence or absence of symptoms that satisfy certain criteria or not. This allows the diagnostic distinction present or absent.

- The dimensional approach that also takes into account the degree in which symptoms are present or absent.

- A combination of the categorical and dimensional approach. This allows diagnostic models that use both representations in dimensions and categories, having a greater predictive validity than either approach alone.

There is an unquestionable consensus that future classification approaches should adopt and incorporate significant and continuous dimensions that can be conceptualised as diagnostic specifiers in terms of genetic factors, neural substrates, biomarkers, background, personality traits, cognitive and affective deficits, the development of the disorder and the response to therapy, to name the most significant.

As we have already seen, throughout history there have been many different approaches, but certain approaches were embraced more readily and were more sociologically acceptable than others in each era. An approach becomes the dominant one depending on its sociological acceptance or through the marketing used. This is important, as groups that advocate for a particular approach improve its chances of gaining importance, social recognition, the hiring of personnel, the acquisition of resources, scholarships etc ${ }^{16}$.
The objective measurement of intelligence requires obtaining standards that take into account a loss over time. Physiological Impairment was defined by Weschler ${ }^{17}$ using the classic formula: Tests maintained - tests not maintained, divided by those maintained $\mathrm{x}$ 100 , giving a percentage that represents a specific regression. In Weschler's stratification, a percentage decline of over $20 \%$ after age correction is a clear indicator of a pathological condition (Weschler).

Until 18 May 2013, both ICD-10 ${ }^{18}$ and DSM-IV ${ }^{19}$ classified dementia with a causal categorical approach and according to the cause or disease that led to its appearance. DSM-5 replaces the "Delirium, Dementia, Amnestic and other cognitive disorders" section with Mild Neurocognitive Disorder or Severe Neurocognitive Disorder ${ }^{20}$, namely a dimensional approach which also specifies the cause. (Dementia with Lewy bodies etc.).

Given the universal acceptance of the term and concept of dementia and its age and evolution over the course of more than two thousand years, we wonder if its elimination was justified. We merely value the progressive expansion of professionals involved in various interests and in numerous, non-medical fields such as copyright of instruments, therapies without over the counter, social politics, etc. A possible narcissistic gratification would not be impossible.

Perhaps the most radical novelty following the disappearance of the term 'dementia' is the appearance of the term Mild Neurocognitive Disorder as a separate entity, seeing Neurocognitive Disorder as equivalent to the modern concept of dementia. It is essentially the same idea, with slight variations. Petersen's introduction of Mild Cognitive Impairment (MCI ${ }^{21}$ sparked considerable controversy that is still to be resolved. MCI can be considered a preliminary stage of $\mathrm{AD}$, yet 
post-mortem studies show normal subjects tested for amyloid deposits have identical results to those affected by MCI, making the value of these amyloid deposits a questionable robust marker ${ }^{22}$. It is important to remember that in 2006 Petersen himself (member of the DSM-5 Cognitive Disorders Committee) wrote an article entitled, 'Mild cognitive impairment should be considered for DSM-5 ${ }^{\prime 21}$. By creating the type Mild Neurocognitive Disorder, MCI became official.

DSM 5 adopts the dimensional approach to create a super category -Cognitive Disorder- as a continuum which, once established, is arbitrarily divided into Mild Neurocognitive Disorder and Severe Neurocognitive Disorder according to psychometric set scores, separated into one, two or more D.S. ${ }^{20}$. This implies the need for scales with age-corrected scores. But the distinction between mild/severe is arbitrary in the forming of a continuum, as it is difficult to establish thresholds (DSM-5 p.208). The differential diagnosis of Neurocognitive Disorder with Normal Cognition "poses a challenge because the boundaries between them are unavoidably arbitrary" (DSM-5 paragraph 4 Normal Cognition). The same text recommends the use of specialised instruments that are capable of quantitatively assessing all abilities. However, it fails to mention that overall short tests (widely used with an optimistic approach) are insensitive to slight changes and to premorbid subjects with a high educational level and, conversely, overly sensitive to subjects of a low educational level.

DSM-5 itself ${ }^{20}$ considers that Severe Neurocognitive Disorder (dementia) may affect between 1-2\% of individuals aged 65-year or more and $30 \%$ of individuals aged 85 -years or more, and the prevalence of MCI may be $2-10 \%$ in individuals aged 65 -year or more and $5-25 \%$ in individuals aged 85 -years or more. If we make a simple calculation, we can see that it could affect $55 \%$ of the planet's total population. The population would suffer social and medical consequences, affecting social security and private insurance professionals, disabilities, wills, etc, in case they are diagnosed in these categories ${ }^{22}$.

This fact is reflected in a US Social Security Adm. document ${ }^{23}$ that considers:

1. That basal rates of mental disorders that include subjects with a mild impairment will increase after receiving formal diagnosis.

2. That the meaning and perception of "functioning" are changed to link it to the diagnosis.

3. That the inclusion of a dimensional severity rate adds information and may improve the identification of disability.

The controversy sparked on 18 May 2013 with the publication of DSM-5, that reached government agencies and even the specialist and daily press ${ }^{24}$. It is interesting to analyse the following chronological development. On April 2nd. 2013, President Obama announced the investment of $\$ 100$ million in 2013 for the BRAIN Initiative Program ${ }^{25}$, an initiative that prioritises areas such as genetics and neuroimaging. On 29 April, NIH Director Thomas Insel announced the disengagement of the agency from "research projects that are solely based on DSM-5 approaches" 26 in favour of the DRC developed by the Institute itself. On 13 May 2013, the APA and NIH issued a joint press release stating that "the diagnostic categories of DSM-5/DSM-IV and ICD-10 contain virtually the same codes and continue to be the contemporary standard consensus by which mental disorders are diagnosed and treated"27. In a public presentation on 18 May, David Kupfer, Chair of the DSM-5 Task Force, stated that the $\$ 25$ million cost justifies the $\$ 198$ sale price for the DSM 5 book, required for the APA to recover the investment. 
The WHO conducted a study/survey ${ }^{28}$ (C. Reed et al W. Psych) of 5,000 psychiatrists from 44 countries that revealed that $70 \%$ of participants used ICD-10 criteria, whilst only 23\% used DSM-IV. Separating European psychiatrists from the rest of the group, they found that out of the 2,700 participants, $80 \%$ used ICD-10 and 13\% used DSM-IV. We do not expect that European professionals would use a commercial product issued by one particular professional association in America.

This situation raises the issue of trying to achieve excellence in diagnosis for our patients, implying the need to consider multiple aspects: background, a psychopathological examination carried out by trained professionals, genetics, neuroimaging, laboratory, development, therapeutic effect etc. without the fear of rethinking diagnosis if needed, prioritising knowledge over faith when it comes to classification. In the long run, the options available are not the best or the strongest but rather those that have proved to be most resilient. In the words of Catalan poet M. Marti $\mathrm{Pol}^{29}$, from his wheelchair: "Tot està per fer i tot és possible"; everything is still to be done and everything is possible.

In conclusion the approach in DSM 5 that proposes both Mild and Major Cognitive Disorder is based on psychometric criteria that do not assess relevant psychopathological aspects in dementia symptomathology. Experienced clinicians can hardly accept attributing de facto the same value for all standardized scales. The negative social impact does not seem enough of a reason for eliminating the term "dementia". The legal, social and medical consequences may be extremely negative. For that reason, CIE-10 and DSM-IV criteria are likely to prevail.

\section{Conflict interests}

None.

\section{References}

1. Tito Lucrecio Caro. De Rerum Naturae. De la Naturaleza. Ed. Acantilado. Barcelona. 2012.

2. Marco Tulio Ciceron. De Senectute. Acerca de la Vejez. Ed. Triacastela Madrid. 2001.

3. Oxford English Dictionary. Oxford. 1644.

4. Sobrino F. Sobrino Aumentado o Nuevo Diccionario de las Lenguas Española Francesa y Latina. Ed. J.B. Delamolliere. Lyon. 1791.

5. Boissier de Sauvages de la Croix F: Nosologie Methodique dans laquelle les malades sont ranges par clases suivant le systeme de Sydenham. Ed. Harissan et fils. Paris. 1771.

6. Diderot et Dalembert. Encyclopédie ou Diccionnaire Raisonné des Sciences, des Arts et des Métiers, par una Societé de Gens de Lettres. Vol 4 Ed. Briasson, David, Le Breton, Durand. Paris. 1765; 807-8.

7. Pinel P. Nosographie Philosophique ou La méthode de l'analyse appliquée a la médecine. $6^{\mathrm{a}}$ ed., Paris. 1818. Brosson, ( $1^{\text {a }}$ ed. 1798).

8. Calmeil LF."Démence". Dictionaire de Médicine on Repertoire General des Sciences Médicales. $2^{\mathrm{a}}$ ed. Ed. Bechet. Paris. 1832; 70-85.

9. Esquirol E.:"Démence" in: Dictionaire des Sciences Médicales, par une Societé de Médecins et des Chirurgiens. Ed. Panckouke. Paris. 1812; 280-93.

10. Berrios G. Una Historia de la Psiquiatría Clínica. G. Berrios y R. Porter Eds. Fundación Española de Psiquiatría y Salud Mental. Ed. Triacastella. Madrid. 2012; 51-83.

11. Perusini G. Sul valore nosografico di alcuni reperti istopatologici caratteristiche per la senilitá. Rivista Italiana di Neuropatologia, Psichiatria ed Elettroterapia. 1918; 4: 193-213.

12. Pick A. Senile Hirnatrophie als Grundlage von Herderscheinungen. Wiener Klinische Wocheschrift. 1901; 14: 403-4.

13. Roth M. Senile dementia and his borderlands. In Cole J.O., Barriet M.D. Eds. Psychopathology in the aged. New York. Raven Press. 1980. 
14. Tomlison B, Blessed G, Roth M. et al. Observations on the brain of non-demented old people. Journal of the Neurological Sciences. 1968; 331-356.

15. Barcia D, Orientaciones Doctrinales de la Psiquiatría. Necesidad de un enfoque histórico. En Tratado de Psiquiatría tomo I. Aran Edts. 2000; 3-66.

16. Kuhn TS. The Structure of Scientific Revolution. Chicago University Press. Chicago. 1970.

17. Weschler D. La mesure de L Inteligence de l'Adulte. Presses Universitaires. Paris. 1961.

18. OMS. CIE 10 Trastornos Mentales y del Comportamiento. OMS Meditor. Madrid. 1993.

19. American Psychiatric Association. Manual Diagnóstico y Estadístico de los Trastornos Mentales DSM IV. Masson S.A. 1995.

20. American Psychiatric Association. Guía de Consulta de los criterios diagnósticos del DSM-5 ${ }^{\mathrm{TM}}$. Arlington V.A. Asociación Americana de Psiquiatría. 2013.

21. Petersen RC, O’Brien J. Mild cognitive impairment should be considered for DSM-V. J Geriatr Psychiatry Neurol. 2006; 19(3): 147-54.

22. Okhravi HR, Palmer RM. Mild cognitive impairment: Challenges in research and in practice. Cleve Clin J Med. 2012; 79(12): 853-4.
23. Sharon Jung MA. The impact of the DSM 5 Dimensional Clasification System on Social Security Dissability Insurance and Supplement Security Income Rolls. Indiana University of Pennsylvania. 2013.

24. Sally L, Batel MD. Why the Fuss Over the DSM 5. The New York Times Sunday Review. 2013.

25. The White House. Brain Iniciative. White House. Gov/Brain. 2013.

26. Insel T. Transforming the understanding and treatment of mental illnesses. NIH Director s Blog. National Institute Health. 2013.

27. Insel T, Lieberman J.A. NIH, APA Issue Joint Statement on DSM 5. DSM 5 and RDoC. 2013.

28. Reed GM, Mendoça Coreira J, Esparza P, Saxena S, Maj M. The WPA-WHO Global Survey of Psychiatrists' Attitudes Towards Mental Disorders Classification. World Psychiatry. 2011; 10(2): 118-131.

29. Marti Pol M. L'ámbit de tots els ambits. Edicions 62. Barcelona. 1996.

Corresponding author:

Joaquim Pujol Domenech

E-mail: pujoldomenech@gmail.com 